\title{
PERANCANGAN DAN PEMBUATAN APLIKASI PERMAINAN MEMORY CARD ONLINE BERTEMA KEMERDEKAAN INDONESIA
}

\author{
Edwin Meinardi Trianto ${ }^{1}$, Calvin Alexander Hartono ${ }^{2}$, Titasari Rahmawati ${ }^{3}$ \\ ${ }^{1}$ Program Studi Manajemen Informatika, Fakultas Teknologi Informasi, \\ Insitut Informatika Indonesia Surabaya \\ 1edwin@ikado.ac.id \\ ${ }^{2}$ Program Studi Informatika, Fakultas Teknologi Informasi, Insitut Informatika Indonesia Surabaya \\ ${ }^{2}$ fienjel.minote@gmail.com \\ ${ }^{3}$ Program Studi Sistem Informasi, Fakultas Teknologi Informasi, \\ Insitut Informatika Indonesia Surabaya \\ ${ }^{3}$ tita@ikado.ac.id
}

\begin{abstract}
Abstrak
Perkembangan teknologi pada smartphone menyebabkan segala informasi dan media entertainment terbaru dapat diakses dengan mudah. Akan tetapi, informasi yang diprioritaskan oleh teknologi tersebut hanyalah informasi yang terkenal dan baru saja. Hal ini mengakibatkan informasi sejarah menjadi tidak mudah untuk sampai kepada para generasi muda. Oleh karena itu, dalam Tugas Akhir ini akan dirancang aplikasi permainan berjudul "Memory card Kemerdekaan" yang bertujuan untuk memberikan pembelajaran sejarah perang kemerdekaan melalui permainan. Pembuatan aplikasi ini didasari dari hasil kuesioner yang didapatkan dari berbagai narasumber. Menurut para narasumber, menggunakan media digital dalam proses pembelajaran dapat menambah daya tarik dan perhatian generasi muda. Aplikasi akan dikembangkan menggunakan Unity dengan bahasa pemrograman $\mathrm{C}++$. Metode perancangan yang digunakan adalah throw-away prototyping. Jenis permainan yang akan dibuat adalah memory card game. Permainan memiliki fitur untuk melihat seluruh referensi sejarah yang terdapat di dalam permainan. Selain itu, pemain juga dapat bermain dengan pemain lain menggunakan koneksi internet. Berdasarkan hasil pengujian black box testing, seluruh fitur yang terdapat dalam aplikasi berjalan dengan baik. Pengujian juga dilakukan dengan lebih dari satu perangkat untuk menguji fitur yang menggunakan koneksi internet seperti multiplayer dan chat.
\end{abstract}

Keywords: Sejarah, Memory card game, prototyping, Unity, Black box testing.

\begin{abstract}
The development of technology on smartphones makes all the latest information and entertainment media easily accessible. However, information that prioritized by the technology are information that known well and the recent information one only. This makes historical information difficult to reach young people. Therefore in this Final Project, a game application called "Independence Memory card" will be designed which aims to provide a lesson in the history of independence through game. This application is based on the results of questionnaire that obtained from various speakers. According to the speakers, using digital media in the learning process can add the attractiveness and attention of the younger generation. The application will be developed using Unity with the $C++$ programming language. The design method used throw-away prototyping. The type of game that will be created is memory card game. The game has a feature to view all of historical references which are contained in the game. Apart from that, players
\end{abstract}


are also can play with others using an internet connection. Based on the black box testing results, all the features that contained in the application are run well. Testing is also carried out with more than one device to test the features that use an internet connection such as multiplayer and chat.

Keywords: History, Memory card game, prototyping, Unity, Black box testing.

\section{PENDAHULUAN}

Perkembangan teknologi pada masa kini menyebabkan segalanya menjadi serba canggih, seluruh informasi dan media entertainment terbaru dapat diakses hanya dengan menggunakan smartphone. Dikarenakan banyak sekali media yang cenderung menawarkan sesuatu yang baru dan trending, informasi seperti sejarah mulai terlupakan bagi para generasi muda. Sejarah merupakan hal yang penting bagi Indonesia, sebagai pengingat akan perjuangan pahlawan dan pengorbanan para pahlawan, akan tetapi, karena perkembangan informasi yang pesat dan trending lebih dianggap menguntungkan bagi internet sebagai bisnis, sehingga sejarah hampir tidak diminati diluar sekolah. Meskipun sekolah telah memberi pembelajaran tentang sejarah, keberadaan sejarah dalam kehidupan sehari-hari hampir tidak ada, berbagai macam usaha dalam mengenang sejarah diluar pembelajaran seperti museum sejarah juga tidak cukup.

Berdasarkan masalah di atas, penulis memutuskan untuk membuat dan merancang aplikasi permainan memory card online dengan tema sejarah kemerdekaan indonesia. Penulis memilih permainan memory card sebagai jenis aplikasi permainan tersebut karena dengan aplikasi tersebut dapat dimainkan oleh pemain dengan usia muda. Permainan merupakan salah satu media entertainment terbesar di dunia, hampir setiap orang dengan teknologi pernah memainkan aplikasi permainan, karena itu, dengan merancang aplikasi permainan yang memiliki unsur sejarah, penulis menjadikan permainan sebagai salah satu daya tarik untuk para generasi muda.

\section{LANDASAN TEORI}

\section{A. Game}

Permainan adalah aktivitas yang menyenangkan, karena tujuan utama dari permainan adalah kesenangan dan kepuasan (Sapio, 2017). Karakteristik dan konteks dari permainan dapat dilihat berdasarkan dari elemen permainan tersebut, karena setiap permainan memiliki cara bermain ( gameplay) yang berbeda-beda. 


\section{B. Kemerdekaan Indonesia}

Selain Soekarno dan Hatta, terdapat lebih banyak lagi tokoh yang berjasa akan suksesnya proklamasi. Diikuti dengan perang kemerdekaan Indonesia yang berlangsung selama empat tahun dari 17 Agustus 1945, hingga 27 Desember 1949, terdapat banyak peristiwa dan momen sejarah yang terjadi sebelum Indonesia meraih kemenangan politik terhadap Belanda (Pustaka, 2016).

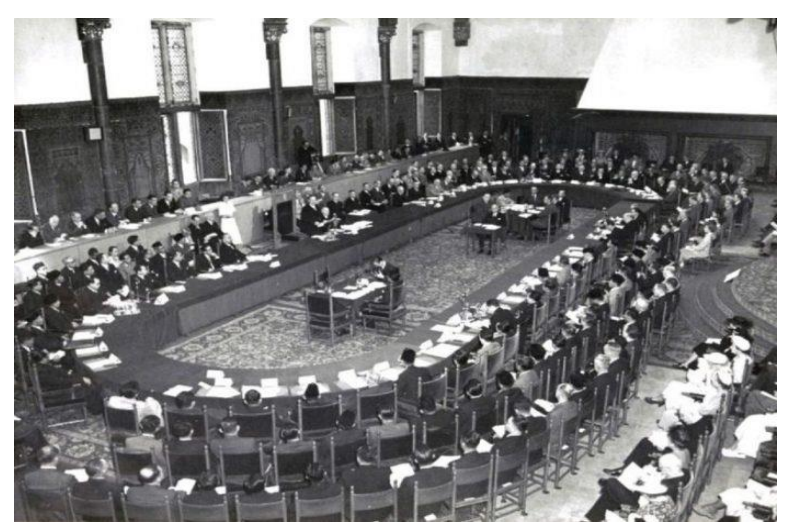

Gambar 1. Konferensi Meja Bundar.

Tahapan-tahapan tersebut dilakukan secara berurutan. Setiap bagian yang sudah selesai dilakukan testing, dikirim ke pemakai untuk langsung dapat digunakan.

\section{Throw-away Prototyping}

Throw-away prototyping memiliki metode untuk menyeleksi prototype yang sudah dibuat apabila prototype tersebut tidak memenuhi tujuan, atau bila prototype tersebut memiliki performa yang sangat buruk, sehingga prototype tersebut tidak dapat dikembangkan lagi (Vallabhaneni, 2017). Throw-away prototype digunakan dalam tahap awal suatu desain dimana terdapat banyak ide yang masih diperhitungkan. Throw-away prototype juga dapat digunakan dalam tahap akhir suatu projek industri, dimana produk yang disediakan memiliki kualitas yang rendah, tetapi memiliki gambaran akan hasil akhir produk tersebut. 


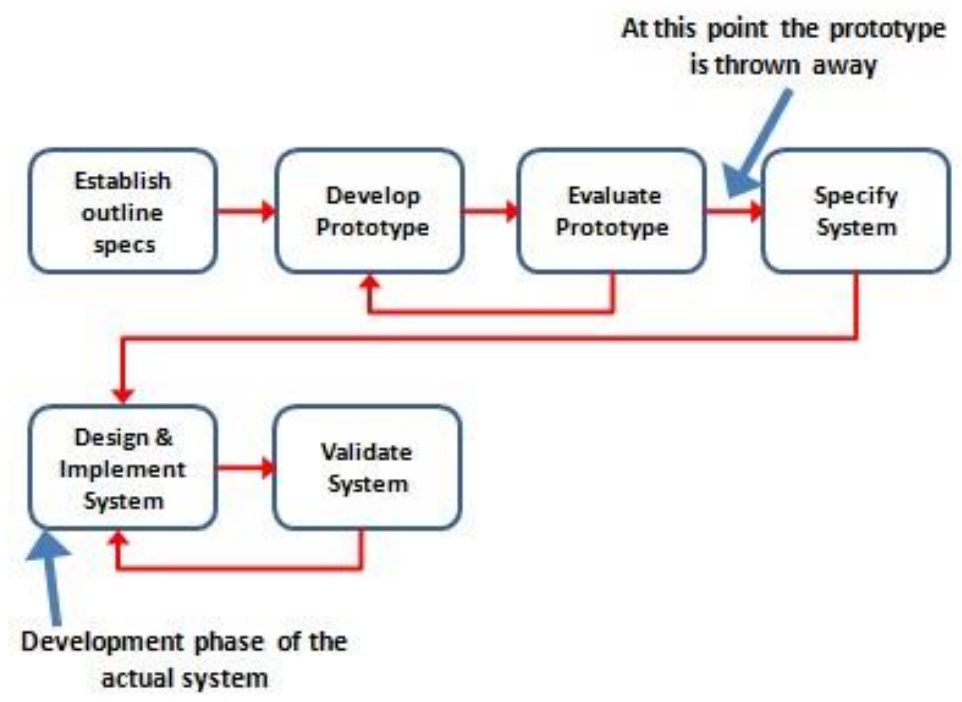

Gambar 2. Throw-away Prototyping

\section{Unity}

Unity adalah game development system yang memiliki kemampuan untuk membuat permainan 2D maupun 3D, bahkan unity sering kali digunakan untuk membuat permainan 3D dikarena seluruh grafik, suara, dan physics engines dalam unity beroperasi dengan baik dalam ruang 3D. Meskipun Unity engine sering digunakan untuk 3D, Unity juga sangat mendukung pembuatan permainan 2D dengan baik (Fowler, 2017).

\section{ANALISIS DAN DESAIN SISTEM}

Pengembangan program atau sistem yang akan dibuat menggunakan metode throw-away prototyping yang dibagi menjadi empat tahap. Dimulai dari desain prototype pertama, desain prototype kedua, desain prototype ketiga, dan yang terakhir adalah implementasi desain interface kedalam permainan.

\section{A. Desain Prototype Pertama (Hand-Sketches Prototype)}

Desain prototype pertama adalah desain yang dibuat untuk mendapatkan saran dari para narasumber, desain prototype pertama dibuat berupa bentuk desain kasar yang dibuat untuk menunjukkan maksud dari hasil akhir yang dibayangkan pembuat aplikasi. 


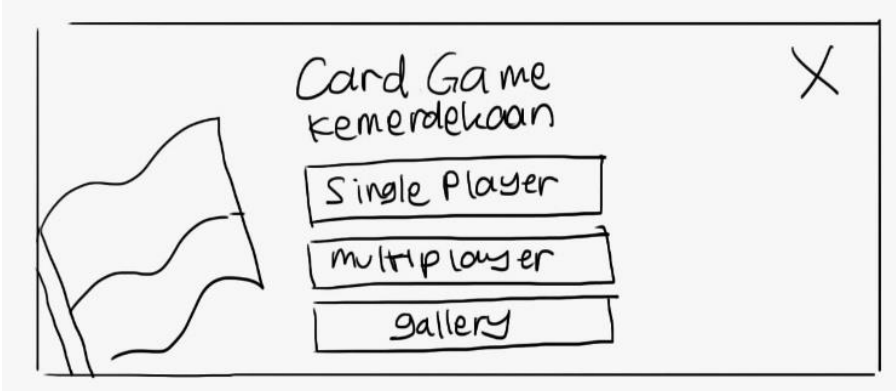

Gambar 3. Desain Prototype Main Menu Pertama Aplikasi Permainan "Memory card Kemerdekaan"

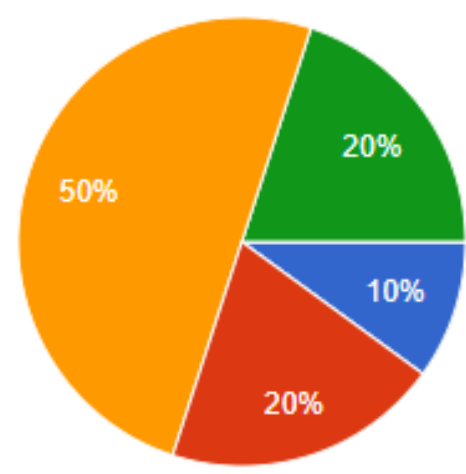

Sangat Bagus

Bagus

Biasa Saja

Jelek

Sangat Jelek

Gambar 4. Grafik Lingkaran Penilaian Desain Prototype Main Menu Pertama

\section{B. Desain Prototype Kedua}

Pada bagian ini, akan dikembangkan desain prototype pertama yang membutuhkan perubahan berdasarkan evaluasi yang didapat dari narasumber pada prototype pertama. Penulis kemudian akan membuat dan memberikan desain protoype kedua tersebut kepada para narasumber untuk dievaluasi.

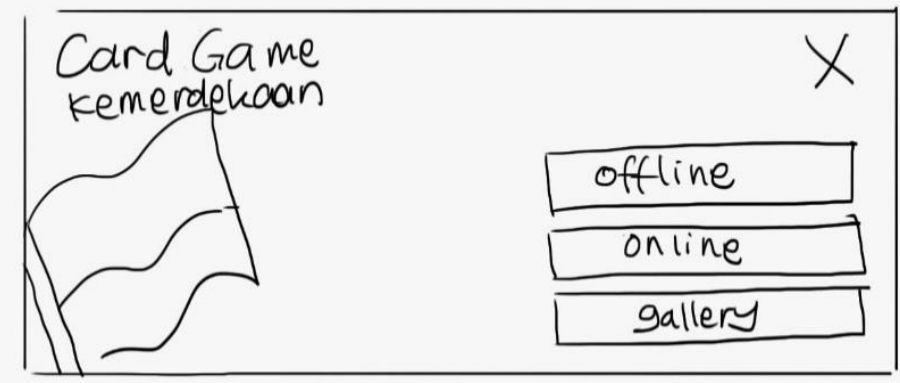

Gambar 5. Desain Prototype Main Menu Kedua Aplikasi Permainan "Memory card Kemerdekaan" 


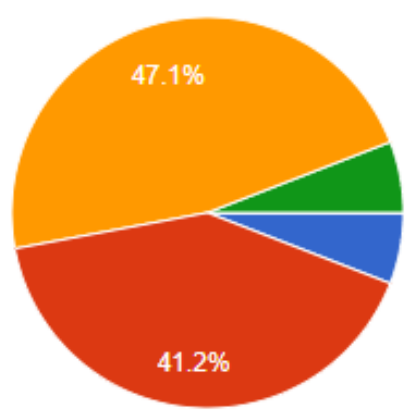

Sangat Bagus

Bagus

Biasa Saja

Jelek

Sangat Jelek

Gambar 6. Grafik Lingkaran Penilaian Desain Prototype Main Menu Kedua

\section{Desain Prototype Ketiga (Hand-Sketches Prototype)}

Pada bagian ini, akan dikembangkan desain prototype kedua yang membutuhkan perubahan berdasarkan evaluasi yang didapat dari narasumber pada prototype kedua. Penulis kemudian akan membuat dan memberikan desain protoype ketiga tersebut kepada para narasumber untuk dievaluasi.

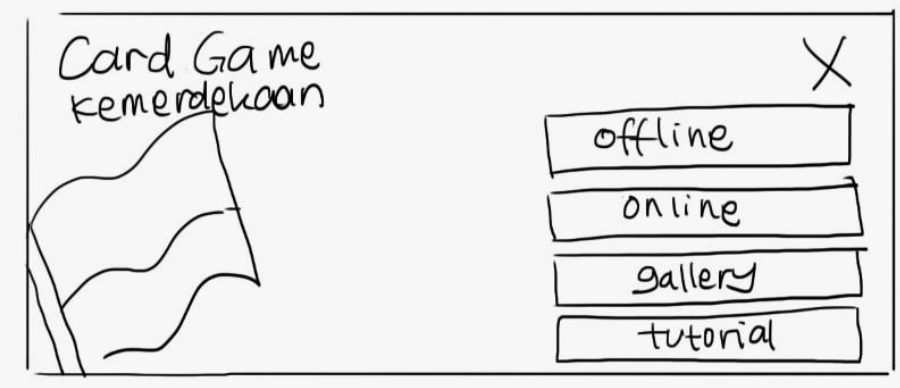

Gambar 7. Desain Prototype Main Menu Ketiga Aplikasi Permainan "Memory card Kemerdekaan"

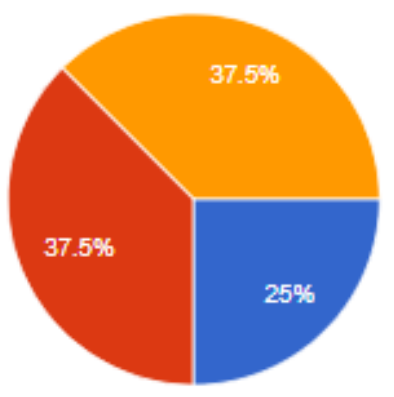




\section{Implementasi Desain Interface Kedalam Permainan}

Dalam tahap throw-away prototyping yang berikutnya, akan dibuat desain interface menggunakan program pembuatan mockup, desain interface dibuat berdasarkan hasil dari prototype sebelumnya. Perancangan interface dapat membantu dalam peletakan bagianbagian interface yang diperlukan dalam permainan.

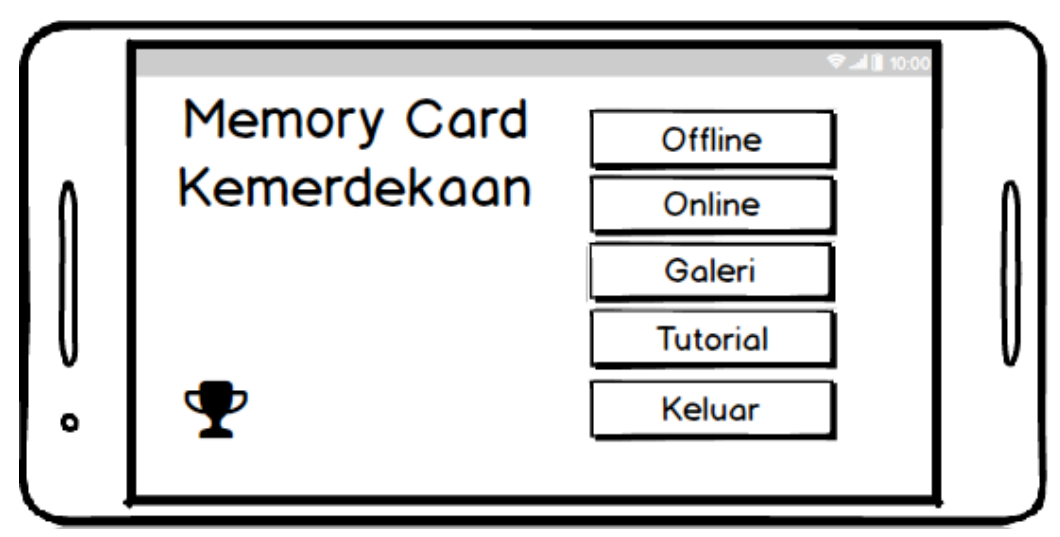

Gambar 9. Desain Interface Main Menu

\section{E. Desain Prosedural}

Desain prosedural perlu dibuat untuk menetapkan detil algoritma yang akan dinyatakan dalam aplikasi permainan. Desain prosedural dibuat setelah menyelesaikan desain sistem, desain arsitektural, dan desain interface.

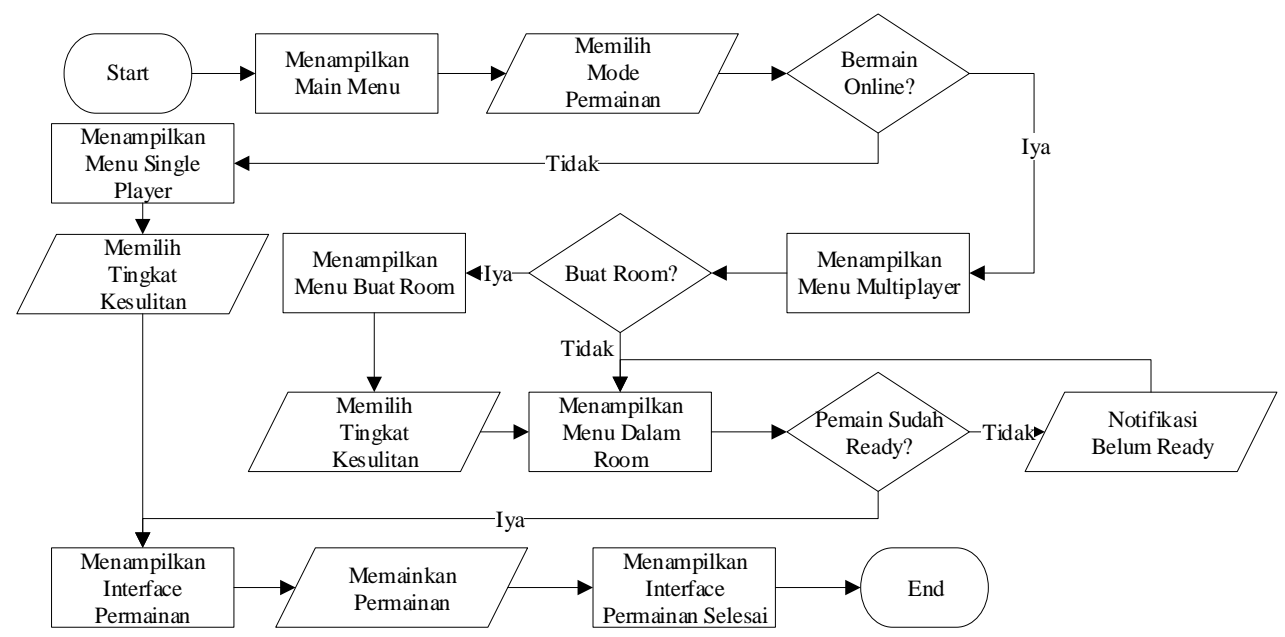

Gambar 10. Proses Memulai Permainan

Pada gambar 10. terlihat diagram alir yang menjelaskan proses bagaimana pemain dapat memulai permainan. Terdapat dua menu berbeda dalam memulai permainan tergantung dari keinginan pemain. Apabila pemain ingin bermain sendiri (single player), 
maka pemain akan dipindahkan kepada menu single player. Dalam menu single player, pemain hanya perlu memilih tingkat kesulitan kemudian permainan akan dimulai. Tetapi apabila pemain ingin bermain dengan pemain lain (multiplayer), maka pemain akan dipindahkan kepada menu multiplayer. Dalam menu multiplayer, pemain harus memilih untuk membuat room atau memasuki room yang sudah dibuat oleh pemain lain. Apabila pemain ingin membuat room, pemain akan dipindahkan kepada menu buat room dan membuat room tersebut setelah selesai memilih tingkat kesulitan. Pemain yang memilih untuk memasuki room dapat langsung memilih room yang sudah ada. Di dalam room. pemain harus memilih nama dan menekan tombol ready agar permainan dapat dimulai.

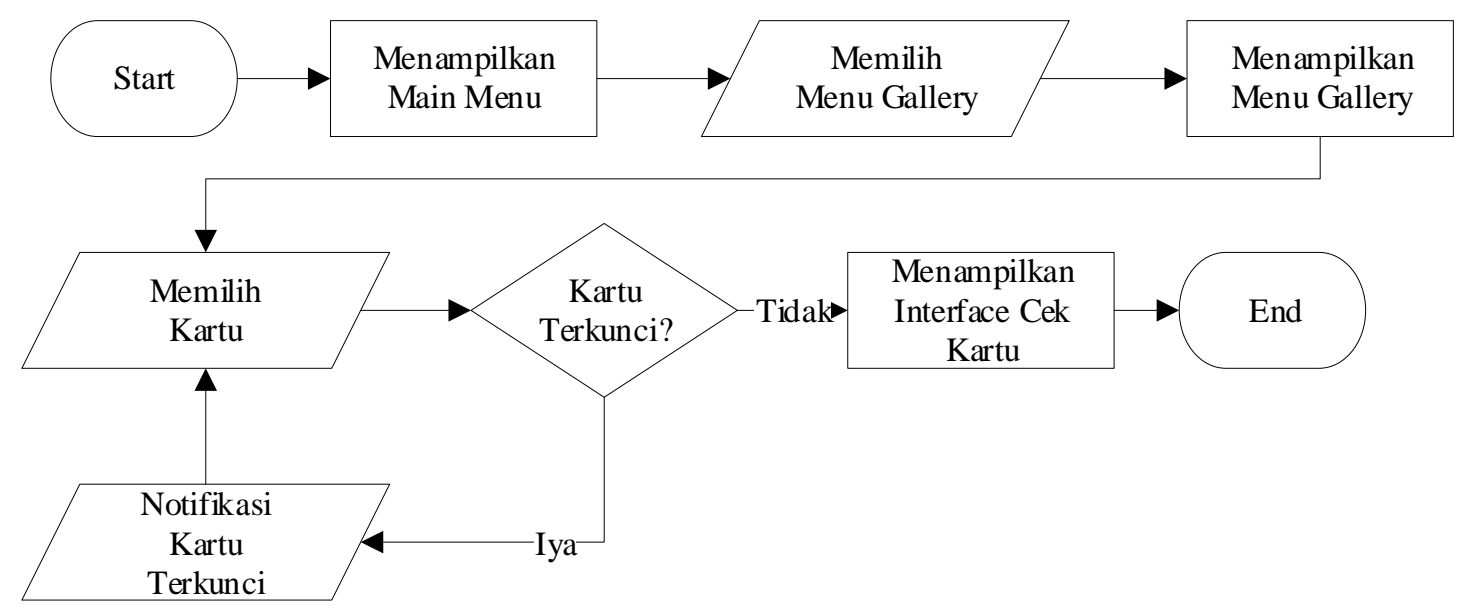

Gambar 11. Diagram Alir Proses Membuka Gallery Permainan

Pada gambar 11. terlihat diagram alir yang menjelaskan proses bagaimana pemain dapat membuka gallery dan mengecek kartu. Untuk membuka gallery, pemain harus memilih menu gallery tersebut dari main menu. Setelah gallery terbuka, pemain dapat memilih kartu untuk melihat nama dan deskripsi kartu tersebut. Apabila kartu masih terkunci, pemain tidak akan dapat melihat detail dari kartu tersebut. 


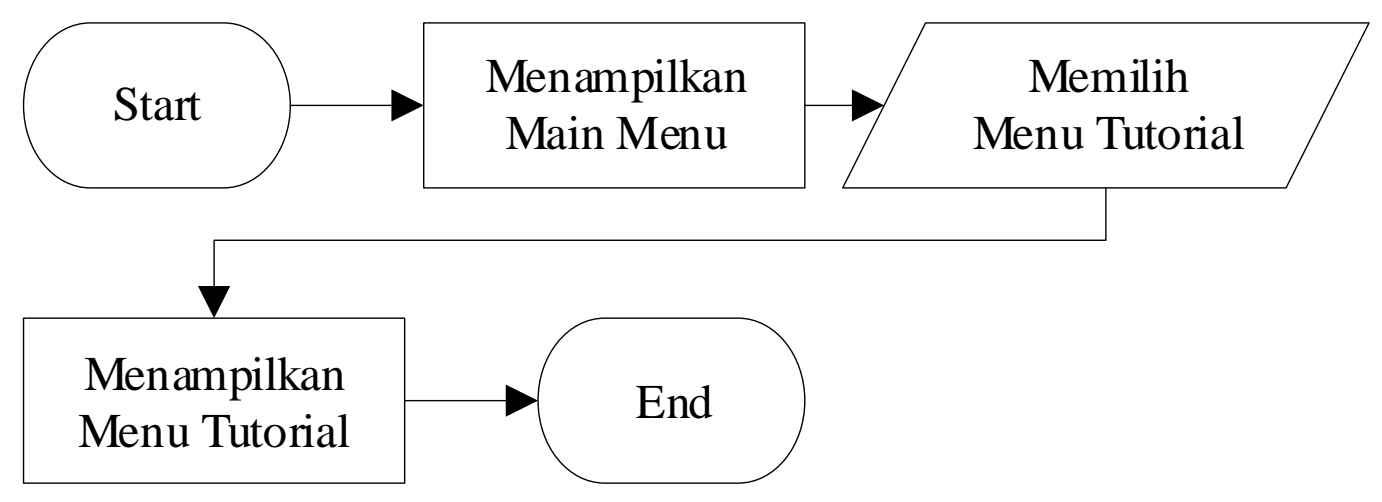

Gambar 12. Diagram Alir Proses Membuka Tutorial Permainan

Pada gambar 12. terlihat diagram alir yang menjelaskan proses bagaimana pemain dapat membuka tutorial permainan untuk mempelajari cara bermain. Untuk membuka tutorial, pemain harus memilih menu tutorial tersebut melalui Main Menu. Kemudian sistem akan menampilkan menu tutorial yang akan memberikan petunjuk cara memainkan permainan.

\section{F. Elemen Permainan "Memory card Kemerdekaan"}

Dalam permainan "Memory card Kemerdekaan" terdapat salah satu elemen permainan yaitu latar belakang. Dalam permainan ini terdapat 2 latar belakang utama yaitu latar belakang pada main menu dan latar belakang saat permainan berlangsung

Pada permainan "Memory card Kemerdekaan", terdapat latar belakang yang digunakan untuk memberikan dekorasi visual terhadap permainan. Dekorasi visual tersebut dipilih karena sesuai dan cocok dipasang dalam permainan. Berikut ini beberapa latar belakang yang akan digunakan antara lain.

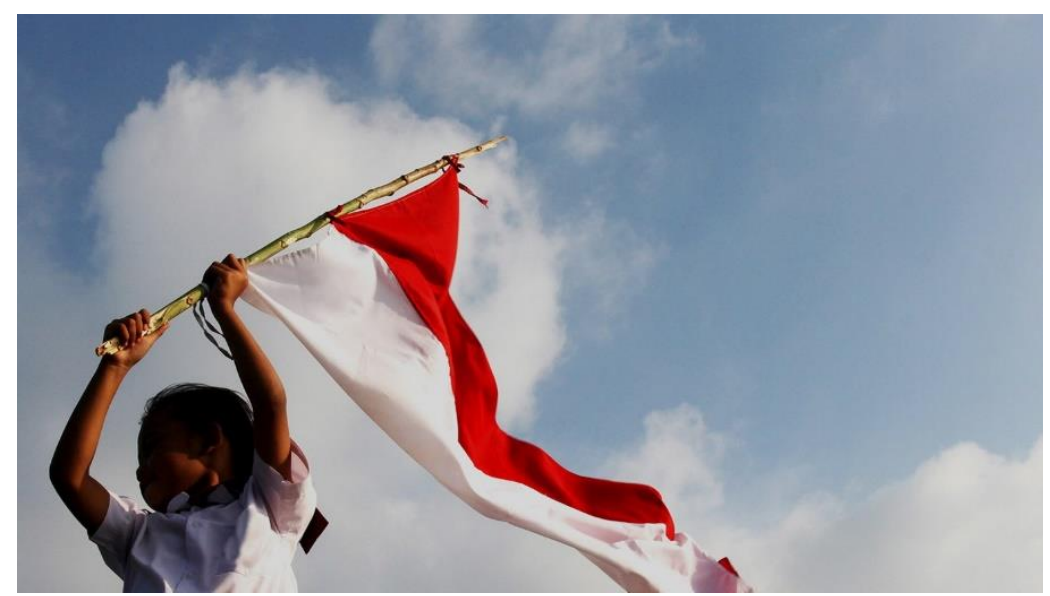

Gambar 13. Latar Belakang Main Menu Permainan 
Pada gambar 13. terlihat gambar yang dijadikan latar belakang permainan. Gambar tersebut dipilih karena gambar tersebut sungguh cocok dengan tema kemerdekaan. Selain itu, warna gambar yang cerah membuatnya mudah untuk dimasuki dengan berbagai macam elemen tambahan seperti judul permainan dan tombol.

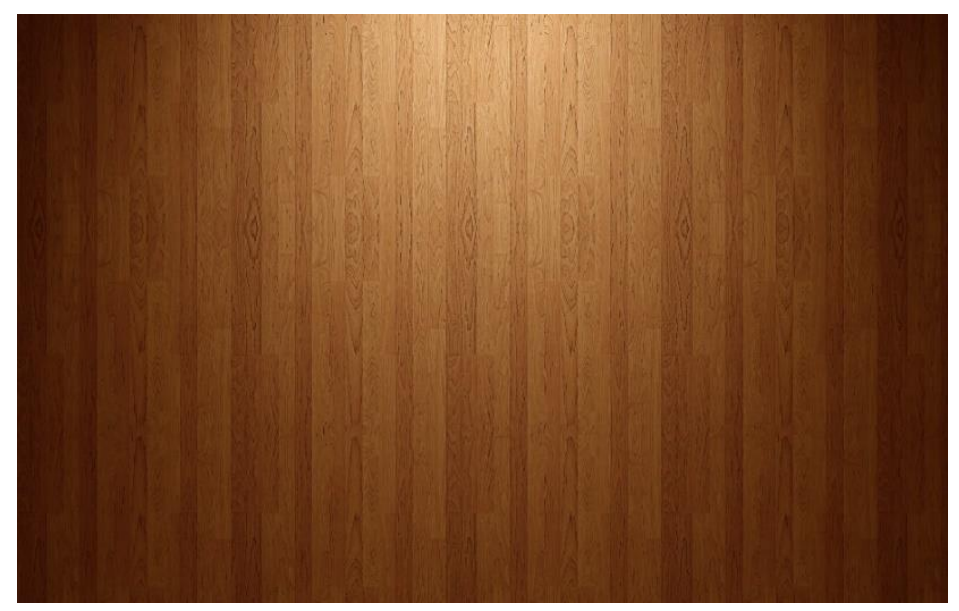

Gambar 14. Latar Belakang Saat Bermain

Pada gambar 14. terlihat gambar yang dijadikan latar belakang permainan. Meskipun latar belakang tersebut hanyalah pola kayu, desain gambar tersebut termasuk cocok dengan permainan dikarenakan cara bermain Memory card Kemerdekaan membutuhkan konsentrasi yang tinggi, sedangkan gambar tersebut memiliki suasana yang menenangkan.

\section{G. Spesifikasi Perangkat Keras dan Perangkat Lunak}

Agar aplikasi dapat bekerja dengan baik, maka diperlukan spesifikasi minimum dari smartphone untuk aplikasi "Memory card Kemerdekaan" dan spesifikasi minimum dari komputer untuk server yang digunakan permainan.

1. Spesifikasi minimal smartphone:

- Ukuran layar 5 inci dan resolusi 720 x 1280 pixels.

- Ruang Memory kosong 512 MB.

- WLAN untuk koneksi internet dalam mode multiplayer.

- Android 6.0.1. (Marshmallow), Marshmallow merupakan sistem operasi utama yang digunakan untuk pengembangan aplikasi. 
2. Spesifikasi minimal server:

- Sistem Operasi Windows 10, Windows 10 merupakan sistem operasi utama yang digunakan untuk mengembangkan server.

- Ruang Memory kosong 512 MB.

- WLAN dan Router yang memiliki kapabilitas port forwarding atau virtual server untuk koneksi internet mode multiplayer.

- Memiliki akses pada alamat website yang digunakan sebagai dynamic DNS untuk koneksi server dan client.

\section{H. Spesifikasi Sistem yang Dihasilkan}

Bagian ini berisi tentang kebutuhan fungsional dan non-fungsional dari sistem yang dihasilkan.

1. Kebutuhan Fungsional

- Memiliki fitur drag dan touch screen.

- Memiliki fitur menampilkan permainan dengan kartu bertema sejarah.

- Memiliki fitur multiplayer dan global chat.

2. Kebutuhan Non-Fungsional

- Memperkenalkan kembali momen penting sejarah perang kemerdekaan.

- Permainan tidak berbayar dan dapat diakses sewaktu-waktu.

- Aplikasi dirancang agar menarik minat baca anak dalam membaca sejarah kemerdekaan Indonesia.

\section{UJI COBA}

Uji coba yang dilakukan pada permainan “Memory card Kemerdekaan” dilakukan dengan menggunakan metode black box testing. Black box testing adalah metode yang berfokus pada pengujian persyaratan fungsional perangkat lunak untuk mendapatkan serangkaian kondisi output. Dengan black box testing dapat diketahui kesesuaian output berdasarkan skenario pengujian yang dipersiapkan dalam proses uji coba. Setelah dilakukan uji coba menggunakan black box tesing, akan dilakukan implementasi kuesioner kepada pengguna aplikasi untuk mengukur seberapa baik aplikasi ini dibuat Berikut beberapa scenario yang diuji coba. 


\section{A. Pengujian Main Menu}

\begin{tabular}{|c|l|l|c|}
\hline No & \multicolumn{1}{|c|}{ Aksi Pengujian } & \multicolumn{1}{|c|}{ Hasil yang diharapkan } & Kesimpulan \\
\hline 1 & Penggunaan tombol Offline & $\begin{array}{l}\text { Halaman menu utama berpindah } \\
\text { ke menu single player }\end{array}$ & Berhasil \\
\hline 2 & Penggunaan tombol Online & $\begin{array}{l}\text { Halaman menu utama berpindah } \\
\text { ke menu multiplayer }\end{array}$ & Berhasil \\
\hline 3 & Penggunaan tombol Galeri & $\begin{array}{l}\text { Halaman menu utama berpindah } \\
\text { ke menu gallery }\end{array}$ & Berhasil \\
\hline 5 & Penggunaan tombol Tutorial & $\begin{array}{l}\text { Halaman menu utama berpindah } \\
\text { ke menu tutorial }\end{array}$ & Berhasil \\
\hline 6 & $\begin{array}{l}\text { Penggunaan tombol High } \\
\text { score }\end{array}$ & $\begin{array}{l}\text { Halaman menu utama berpindah } \\
\text { ke menu high score }\end{array}$ & Berhasil \\
\hline & & & Keluar dari permainan \\
\hline
\end{tabular}

Tabel 1. Skenario Uji Coba Main Menu

\section{B. Pengujian Kondisi Akhir Tombol Gallery}

\begin{tabular}{|c|l|l|c|}
\hline No & \multicolumn{1}{|c|}{ Aksi pengujian } & \multicolumn{1}{|c|}{ Hasil yang diharapkan } & Kesimpulan \\
\hline 1 & Pindah Halaman Gallery & $\begin{array}{l}\text { Memindah halaman gallery untuk } \\
\text { melihat kartu lain. }\end{array}$ & Berhasil \\
\hline 2 & Melihat Detail Kartu & $\begin{array}{l}\text { Melihat detail dari kartu yang dapat } \\
\text { dibuka. }\end{array}$ & Berhasil \\
\hline 3 & Ganti Kategori Kartu & $\begin{array}{l}\text { Menggunakan fitur ganti kategori } \\
\text { untuk mencari kartu dengan kategori } \\
\text { tertentu. }\end{array}$ & Berhasil \\
\hline
\end{tabular}

Tabel 2. Skenario Uji Coba Tombol Gallery 


\section{Pengujian Kondisi Akhir Tombol Tutorial}

\begin{tabular}{|c|c|lr|c|}
\hline No & Jenis pengujian & \multicolumn{2}{|c|}{ Hasil yang diharapkan } & Kesimpulan \\
\hline 1 & Pindah Halaman Tutorial & $\begin{array}{l}\text { Memindah halaman } \\
\text { tutorial untuk melihat } \\
\text { instruksi lain. }\end{array}$ & Berhasil \\
\hline
\end{tabular}

Tabel 3. Skenario Uji Coba Tombol Tutorial

\section{Pengujian Kondisi Akhir Menu Single Player}

\begin{tabular}{|c|l|l|c|}
\hline No & \multicolumn{1}{|c|}{ Aksi pengujian } & \multicolumn{1}{|c|}{ Hasil yang diharapkan } & Kesimpulan \\
\hline 1 & $\begin{array}{l}\text { Memilih Tingkat } \\
\text { Kesulitan }\end{array}$ & $\begin{array}{l}\text { Permainan menunjukkan deskripsi } \\
\text { dari tingkat kesulitan yang dipilih. }\end{array}$ & Berhasil \\
\hline 2 & Memilih Kategori Kartu & $\begin{array}{l}\text { Permainan menutup tingkat } \\
\text { kesultian apabila jumlah kartu } \\
\text { terlalu sedikit. }\end{array}$ & Berhasil \\
\hline 3 & Memasuki Permainan & $\begin{array}{l}\text { Memulai permainan setelah } \\
\text { memilih tingkat kesulitan. }\end{array}$ & Berhasil \\
\hline
\end{tabular}

Tabel 4. Skenario Uji Coba Menu Single Player

\section{E. Pengujian Kondisi Akhir Menu Multiplayer}

\begin{tabular}{|c|l|l|c|}
\hline No & \multicolumn{1}{|c|}{ Aksi Pengujian } & \multicolumn{1}{|c|}{ Hasil yang diharapkan } & Kesimpulan \\
\hline 1 & Mengirim Chat & $\begin{array}{l}\text { Permainan mengirim pesan chat } \\
\text { kepada seluruh pemain. }\end{array}$ & Berhasil \\
\hline 2 & Membuat Room & $\begin{array}{l}\text { Permainan membuat room yang } \\
\text { dapat dimasuki oleh pemain lain. }\end{array}$ & Berhasil \\
\hline 3 & Memasuki Room & $\begin{array}{l}\text { Permainan memasuki room yang } \\
\text { diinginkan. }\end{array}$ & Berhasil \\
\hline 4 & Menekan Tombol Ready & $\begin{array}{l}\text { Permainan mengirim data menuju } \\
\text { server bahwa pemain siap untuk } \\
\text { memulai permainan. }\end{array}$ & Berhasil \\
\hline 5 & Menekan Tombol Start & $\begin{array}{l}\text { Permainan memulai permainan } \\
\text { secara online. }\end{array}$ & Berhasil \\
\hline
\end{tabular}

Tabel 5. Skenario Uji Coba Menu Multiplayer 


\section{F. Pengujian Kondisi Akhir Menu Permainan}

\begin{tabular}{|c|l|l|c|}
\hline No & \multicolumn{1}{|c|}{ Aksi pengujian } & \multicolumn{1}{|c|}{ Hasil yang diharapkan } & Kesimpulan \\
\hline 1 & Membuka Interface & $\begin{array}{l}\text { Pemain menggunakan tombol } \\
\text { panah untuk membuka interface } \\
\text { kartu. }\end{array}$ & Berhasil \\
\hline 2 & Memilih Kartu & $\begin{array}{l}\text { Permainan memilih dua kartu untuk } \\
\text { dibandingkan. }\end{array}$ & Berhasil \\
\hline 3 & Drag Kamera & $\begin{array}{l}\text { Permainan menggeser kamera } \\
\text { dengan fitur drag pada touch screen. }\end{array}$ & Berhasil \\
\hline 5 & Zoom Kamera & $\begin{array}{l}\text { Permainan melakukan zoom in dan } \\
\text { out di dalam permainan. }\end{array}$ & Berhasil \\
\hline 6 & $\begin{array}{l}\text { Reset Kamera } \\
\text { Kartu }\end{array}$ & $\begin{array}{l}\text { Permainan mengembalikan posisi } \\
\text { kamera seperti semula dengan } \\
\text { tombol reset kamera. }\end{array}$ & Berhasil \\
\hline 7 & $\begin{array}{l}\text { Keluar } \\
\text { Permainan }\end{array}$ & $\begin{array}{l}\text { Permainan membuka ukuran asli } \\
\text { kartu dengan menekan gambar kartu } \\
\text { yang muncul pada interface. }\end{array}$ & Berhasil \\
\hline Demanan & $\begin{array}{l}\text { Pemain memenangkan permainan } \\
\text { dengan memilih seluruh pasang } \\
\text { kartu yang sama. }\end{array}$ & Berhasil \\
\hline Pemain keluar dari permainan & Berhasil \\
\hline 5
\end{tabular}

Tabel 6. Skenario Uji Coba Menu Permainan

\section{Kesimpulan}

Akan dijelaskan beberapa kesimpulan yang dapat diambil dari perancangan dan pembuatan aplikasi permainan memory card online bertema kemerdekaan indonesia. Kesimpulan yang dapat diambil antara lain:

1. Dengan memanfaatkan unity networking, aplikasi permainan "Memory card Kemerdekaan" dapat menggunakan berbagai macam fitur networking sehingga aplikasi permainan dapat dimainkan secara online.

2. Dengan menggunakan koneksi internet, seorang pemain yang berlaku sebagai client, dapat memainkan aplikasi permainan "Memory card Kemerdekaan" secara 
online dengan pemain lain. Dibutuhkan sebuah komputer yang digunakan sebagai server untuk menerima koneksi dari setiap client yang terhubung.

3. Penggunaan development platform Unity dalam pengembangan aplikasi permainan dapat mempermudah pembuatan aplikasi permainan memory card, karena Unity memiliki tampilan yang baik dan mudah dipelajari. Fitur drag and drop yang dimiliki oleh Unity juga mempermudah pengembangan desain permainan. Terutama dalam menerapkan dan menampilkan berbagai informasi detil sejarah perang kemerdekaan, sehingga dapat dipelajari oleh pemain.

4. Dengan metode pengembangan throw-away prototyping, penulis dapat mengembangkan sistem permainan dengan desain interface yang dinilai mudah dan jelas berdasarkan pada masukan serta saran dari para narasumber. Berdasarkan hasil kuesioner, dapat dilihat bahwa pengguna sebagian besar memberikan tanggapan positif terhadap penggunaan media digital untuk mendukung proses belajar mengajar.

\section{DAFTAR PUSTAKA}

Sapio, Francesco (2017). Unity 2017 2D Game Development Projects: Create three interactive and engaging 2D games with Unity 2017.Packt, Birmingham.

Pustaka, Bentang. (2016). Indonesia Poenja Tjerita. Bentang Pustaka, Yogyakarta.

Vallabhaneni, S. Rao. (2017). Wiley CIAexcel Exam Review 2017. John Wiley \& Sons, New Jersey.

Fowler, Allan. (2017). Learn Unity 2017 for iOS Game Development: Create Amazing $3 \mathrm{D}$ Games for iPhone and iPad. Appress: America. 
Edwin Meinardi Trianto, Calvin Alexander Hartono, Titasari Rahmawati

Perancangan dan Pembuatan Aplikasi Permainan Memory Card Online Bertema Kemerdekaan Indonesia

(HALAMAN INI SENGAJA DIKOSONGKAN) 